\title{
APOE-dependent PET patterns of brain activation in Alzheimer disease
}

\author{
N. Scarmeas, MD; K.E. Anderson, MD; J. Hilton, PhD; A. Park; C. Habeck, PhD; J. Flynn; \\ B. Tycko, MD, PhD; and Y. Stern, $\mathrm{PhD}$
}

\begin{abstract}
Using $\mathrm{H}_{2}{ }^{15} \mathrm{O}$ PET, the authors imaged 13 patients with Alzheimer disease (AD) while performing a serial nonverbal recognition memory task. Patterns of brain activation differed as a function of APOE genotype: $\epsilon 4$ carriers exhibited lower activation in the left lingual gyrus and higher activation in left cuneus, precuneus, parahippocampal, and right precentral gyrus. The $A P O E$ genotype seems to play a role in cerebral physiologic activity even after onset of clinical manifestations of $\mathrm{AD}$.
\end{abstract}

NEUROLOGY 2004;63:913-915

Although the presence of the $\epsilon 4$ allele has been associated with earlier age of disease onset, its relation to different Alzheimer disease (AD) clinical and phenotypic subtypes is less clear. It is conceivable that the clinical heterogeneity observed in $\mathrm{AD}$ could derive from underlying genetic variability.

Whereas previous studies have investigated the association between $A P O E$ and patterns of brain activation in middle-aged and elderly individuals, ${ }^{1}$ we explored the effect of the $A P O E$ genotype on brain activation in patients with $\mathrm{AD}$.

Methods. Subjects. This was part of a larger imaging study, the details of which are described elsewhere. ${ }^{2}$ Thirteen subjects with early $\mathrm{AD}$ (nine men and four women) who met National Institute of Neurological and Communication Disorders and Stroke/Alzheimer's Disease and Related Disorders Association for probable $\mathrm{AD}$ (reached at a consensus diagnostic conference of neurologists, psychiatrists, and neuropsychologists) were studied. The patients underwent MRI, appropriate laboratory tests, and extensive neuropsychological evaluation, part of which is shown in table E-1 (see table E-1 on the Neurology Web site at www.neurology. org). With the exception of two subjects (one $\epsilon 4$ carrier and one noncarrier) who were taking acetylcholinesterase inhibitors, patients were not receiving any other CNS-acting medications. $A P O E$ or PET activation results did not play any role in the diagnostic process.

Cognitive task. Because APOE-related differential activation during memory tasks has been previously reported ${ }^{1}$ and because nonverbal memory deficits are among the earliest clinical features of $\mathrm{AD}$, we chose a nonverbal episodic memory task for the neuroimaging component of this study. It comprised two conditions (figure, A).

1. A low demand condition (LD), in which a single shape (different each time) was presented during the encoding phase. Dur-

Additional material related to this article can be found on the Neurology Web site. Go to www.neurology.org and scroll down the Table of Contents for the September 14 issue to find the link for this article. ing the recognition phase, either the same shape as the encoding phase or a nonfamiliar foil was presented. Subjects were instructed to make a "new" or "old" response for each probe item by pressing one of two microswitches.

2. A titrated demand (TD) condition involved a serial presentation of several shapes during the encoding phase. The number of shapes was determined in a training session on the day preceding the PET scan, during which shape list size was adjusted in a staircase manner such that recognition accuracy was $\sim 75 \%$ for each subject. The recognition phase of the TD condition involved presentation of shapes studied during the preceding study phase intermixed with nonfamiliar foils.

PET scan acquisition and data processing. Multiple trials of each condition were acquired during scanning. For each scan, a bolus of $30 \mathrm{mCi} \mathrm{H}_{2}{ }^{15} \mathrm{O}$ was injected $\mathrm{IV}$, and nonquantitative counts (relative cerebral blood flow $[\mathrm{rCBF}]$ ) were obtained. Two 30-second scan frames (which were subsequently averaged) were acquired in two-dimensional mode. The SPM99 program was used to implement realignment, spatial transformation, smoothing (isotropic, Gaussian kernel [full width at half-maximum $=12 \mathrm{~mm}$ ]), and proportional scaling by global mean.

General linear model design. Multiple regression analyses were performed at each voxel with $\mathrm{rCBF}$ as the dependent variable. Independent variables were 1 ) the cognitive task condition (TD vs LD); 2) the APOE genotype (dichotomous form, presence vs absence of an $\in 4$ allele); and 3) the cognitive task condition $\times$ $A P O E$ interaction. Our primary interest was the statistical significance of the condition $\times A P O E$ interaction effect, which speaks to the hypothesis that functional activation (TD rCBF after subtracting out $\mathrm{LD}$ rCBF related to basic sensory and motor processing) differs between $\epsilon 4$ allele carriers and noncarriers. The falsepositive rate was controlled at $\alpha=0.05$ per map (Bonferroni corrected for the number of resolution elements).

Results. Demographic/behavioral. Four (of nine) men and two (of four) women were $\epsilon 4$ carriers $(p=0.85$ ). All patients had early AD: mean modified Mini-Mental State Examination score was 46 of 57 (corresponding to a Folstein Mini-Mental State Examination score of $\sim 24$; see table E-1 on the Neurology Web site at www.neurology.org). Although age did not differ between the groups $(p=0.09)$,

From the Cognitive Neuroscience Division of the Taub Institute for Research in Alzheimer's Disease and the Aging Brain (Drs. Scarmeas, Hilton, Habeck, and Stern, A. Park and J. Flynn) and the Departments of Neurology (Drs. Scarmeas and Stern) and Pathology (Dr. Tycko), College of Physicians and Surgeons of Columbia University; New York, NY; and the Department of Psychiatry (Dr. Anderson), University of Maryland, Baltimore, MD.

Supported by US federal grants AG 14671 and RR 00645.

Received October 19, 2003. Accepted in final form May 5, 2004.

Address correspondence and reprint requests to Dr. Nikolaos Scarmeas, Columbia Presbyterian Medical Center, 622 West 168 th Street, PH 19th floor, New York, NY 10032; e-mail: ns257@columbia.edu 


\section{Low Demand Condition}

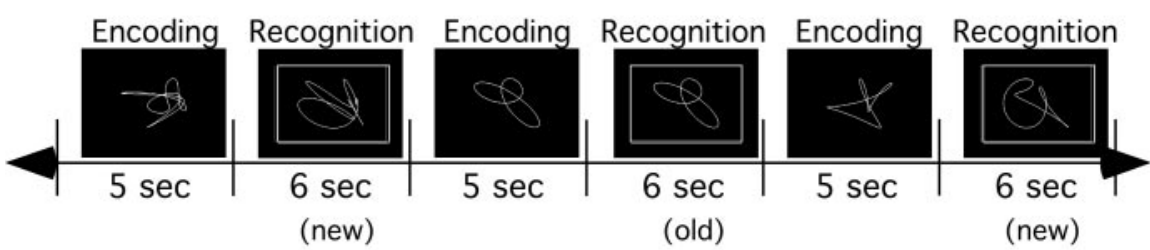

Titrated Demand Condition

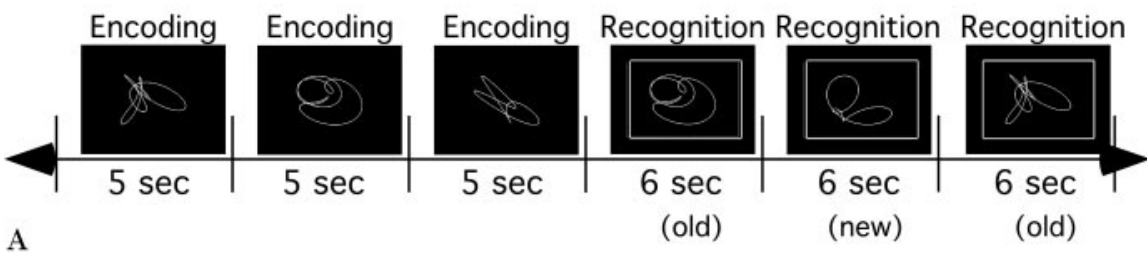

A

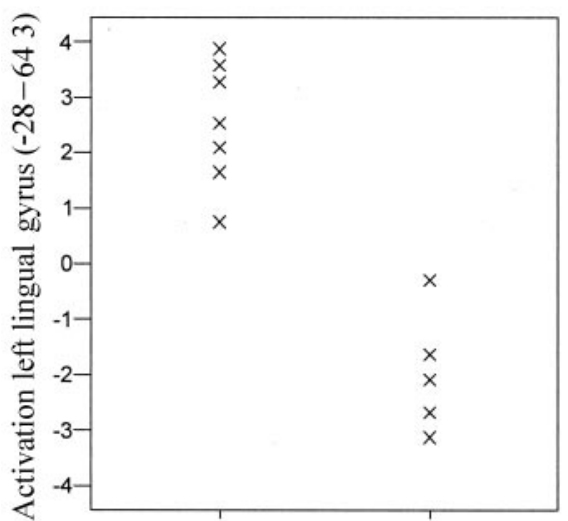

B

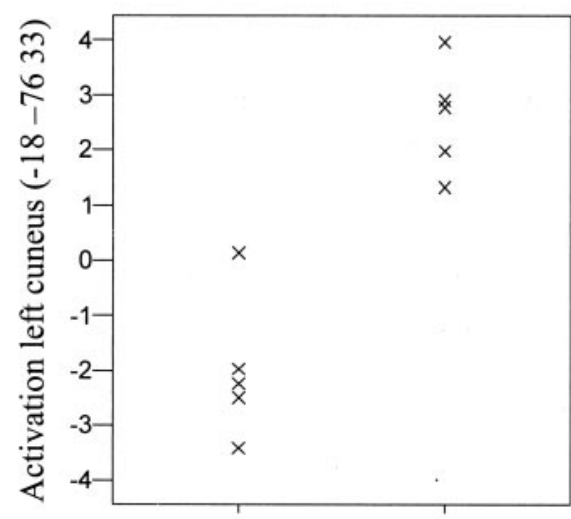

$\begin{array}{cc}\text { Absent } & \text { Present } \\ \varepsilon 4 & \varepsilon 4\end{array}$
Figure. (A) Nonverbal memory task. Shape list size varied for the titrated demand condition so that each patient's performance was $\sim 75 \%$ accurate. For presentation purposes, a list size of three shapes during the titrated demand condition is illustrated here. During study phases, subjects were exposed to each stimulus for 5 seconds, while a 6 -second response time limit was imposed during the recognition phase. (B) Graphs plot relative cerebral blood flow $(r C B F)$ activation for the two groups in regions where global maxima of significance were noted. Note the clear $r C B F$ separation between the $\epsilon 4$ carriers and noncarriers in these two regions. *The number of points in the graphs is less than the number of subjects because of close proximity of some activation values, which makes them appear as single points. two $\epsilon 4$ carriers had early age of disease onset (symptoms starting at ages 45 and 53 years), resulting in $\epsilon 4$ carriers being on average 10 years younger. Because patients with early-onset $\mathrm{AD}$ are considered by many to represent a separate group not only in terms of age but also in terms of many other clinical or biologic measures, we explored the effect of removing the early-onset patients from the $\epsilon 4$ carrier group (which resulted in almost identical age dis- tributions in both $A P O E$ groups): the imaging analysis results were unchanged. Education and neuropsychological performance did not differ statistically among the groups. To further ensure that the two groups were cognitively equivalent, we included Selective Reminding Test delayed recall performance as a covariate in supplementary imaging analyses: the results were similar. The following shape list sizes were used during the TD condition: 2 (two sub-

Table Areas where significant associations between brain activation and APOE (presence vs absence of $\varepsilon 4$ ) were detected (p $<0.05$ Bonferroni corrected) in the SPM analyses

\begin{tabular}{|c|c|c|c|c|c|c|c|}
\hline & \multicolumn{3}{|c|}{$\begin{array}{c}\text { Talairach } \\
\text { coordinates }\end{array}$} & \multirow{2}{*}{$\begin{array}{l}\text { T values } \\
(d f=30)\end{array}$} & \multirow{2}{*}{$\begin{array}{l}\text { Cluster size } \\
\text { (\# voxels) }\end{array}$} & \multirow{2}{*}{$\begin{array}{l}R^{2} \text { (variance } \\
\text { explained) }\end{array}$} & \multirow[b]{2}{*}{ Location (Brodmann area) } \\
\hline & $\mathrm{x}$ & $\mathrm{y}$ & $\mathrm{z}$ & & & & \\
\hline $\begin{array}{l}\text { Areas where } \varepsilon 4 \text { carriers exhibit } \\
\text { lower rCBF activation }\end{array}$ & -28 & -64 & 3 & 7.7 & 19 & 0.84 & Left lingual gyrus (19) \\
\hline \multirow{4}{*}{$\begin{array}{l}\text { Areas where } \varepsilon 4 \text { carriers exhibit } \\
\text { higher rCBF activation }\end{array}$} & -18 & -76 & 33 & 6.8 & 8 & 0.80 & Left cuneus (7) \\
\hline & 50 & -8 & 34 & 6.6 & 40 & 0.80 & Right precentral gyrus (6) \\
\hline & -38 & -43 & -1 & 5.6 & 3 & 0.74 & Left parahippocampal gyrus (19) \\
\hline & -18 & -56 & 45 & 5.4 & 3 & 0.72 & Left precuneus (7) \\
\hline
\end{tabular}

$\mathrm{rCBF}=$ relative cerebral blood flow. 
jects), 3 (four subjects), 4 (one subject), 5 (two subjects), 6 (three subjects), and 9 (one subject).

PET data. Compared with the subjects without the $\epsilon 4$ allele, $\epsilon 4$ carriers exhibited significant deactivation in the left lingual gyrus (see table and figure, B; also see figure E-1 on the Neurology Web site at www.neurology.org). At the same time, $\epsilon 4$ carriers manifested significantly higher activation in left cuneus, precuneus, right precentral, and parahippocampal gyri.

Discussion. The relation of $A P O E$ to different $A D$ clinical and phenotypic subtypes is debatable. APOErelated clinical heterogeneity after $\mathrm{AD}$ onset is supported by observations reporting that presence of the $\epsilon 4$ allele is associated with increased risk for psychosis, ${ }^{3}$ less risk for development of extrapyramidal signs, ${ }^{4}$ lower rates of cognitive decline, and lower mortality. ${ }^{4} \mathrm{AD}$ patients with the $\epsilon 4$ allele have also been reported to carry increased $\beta$-amyloid and neurofibrillary tangles. ${ }^{5}$ There is controversy regarding $A P O E$ effects on brain tissue atrophy with some structural MRI studies reporting no $A P O E$-related differences in hippocampal volumes, ${ }^{6}$ whereas others have reported greater atrophy in medial temporal structures in AD patients carrying the $\epsilon 4$ allele. ${ }^{7}$ Similarly, resting functional imaging studies after onset of $\mathrm{AD}$ have reported mixed results with some reporting decreased, ${ }^{8}$ increased, ${ }^{9}$ or unchanged ${ }^{10}$ cerebral blood flow or metabolism for the $\epsilon 4$ carriers.

We detected an association between $A P O E$ genotype and cerebral physiologic activity during cognitive activation. This was not a function of differential effort because memory task difficulty was experimentally equated in the two $A P O E$ groups. The detected activation differences indicate altered memory processing in $\mathrm{AD}$ patients with the $\epsilon 4$ allele despite the common underlying pathology. The results argue for an $A P O E$-dependent neurophysiologic heterogeneity among subjects with $\mathrm{AD}$ even after the onset of clinical manifestations of the disease.

Areas with differential activation in the $\epsilon 4$ carriers may reflect malfunctioning (taking the form of either overactivation or deactivation) because of more severe AD pathologic involvement for $\epsilon 4$ carriers in these regions (i.e., parahippocampal gyrus). Alternatively, some of these regions may still be spared by AD pathology (i.e., precentral gyrus) and recruited for task performance by $\epsilon 4$ carriers because of more severe pathologic involvement in other regions. It is also possible that differential activation is not directly related to the degree or localization of pathology but reflects $A P O E$-related cerebral physiologic heterogeneity.

This study has limitations. Because the PET scanning session encompassed the encoding and recognition phase of the task, exact $A P O E$-related neuroanatomic localization for each cognitive process is not possible. Because no arterial sampling was performed, we had to rely on relative flow values rather than absolute quantification of the activations. This study included white, highly educated patients recruited from a university-based dementia referral center, which might limit generalizability to the population. Finally, the small number of participants may have limited power to detect significant age and cognitive differences between carriers and noncarriers; therefore, results should be replicated with a larger sample size.

\section{References}

1. Bookheimer SY, Strojwas MH, Cohen MS, et al. Patterns of brain activation in people at risk for Alzheimer's disease. N Engl J Med 2000;343: 450-456.

2. Scarmeas N, Zarahn E, Anderson KE, et al. Cognitive reserve modulates functional brain responses during memory tasks: a PET study in healthy young and elderly subjects. Neuroimage 2003;19:1215-1227.

3. Scarmeas N, Brandt J, Albert M, et al. Association between the APOE genotype and psychopathologic symptoms in Alzheimer's disease. Neurology 2002;58:1182-1188.

4. Stern Y, Brandt J, Albert M, et al. The absence of an apolipoprotein epsilon4 allele is associated with a more aggressive form of Alzheimer's disease. Ann Neurol 1997;41:615-620.

5. Polvikoski T, Sulkava R, Haltia M, et al. Apolipoprotein E, dementia, and cortical deposition of beta-amyloid protein. N Engl J Med 1995;333: 1242-1247.

6. Jack CR Jr, Petersen RC, Xu YC, et al. Hippocampal atrophy and apolipoprotein $\mathrm{E}$ genotype are independently associated with Alzheimer's disease. Ann Neurol 1998;43:303-310.

7. Hashimoto M, Yasuda M, Tanimukai S, et al. Apolipoprotein E $\epsilon 4$ and the pattern of regional brain atrophy in Alzheimer's disease. Neurology 2001;57:1461-1466.

8. Lehtovirta M, Kuikka J, Helisalmi S, et al. Longitudinal SPECT study in Alzheimer's disease: relation to apolipoprotein $\mathrm{E}$ polymorphism. J Neurol Neurosurg Psychiatry 1998;64:742-746.

9. Higuchi M, Arai H, Nakagawa T, et al. Regional cerebral glucose utilization is modulated by the dosage of apolipoprotein $\mathrm{E}$ type 4 allele and alpha1-antichymotypsin type A allele in Alzheimer's disease. Neuroreport 1997;8:2639-2643.

10. Corder EH, Jelic V, Basun H, et al. No difference in cerebral glucose metabolism in patients with Alzheimer disease and differing apolipoprotein E genotypes. Arch Neurol 1997;54:273-277. 


\section{Neurology}

\section{APOE-dependent PET patterns of brain activation in Alzheimer disease}

N. Scarmeas, K. E. Anderson, J. Hilton, et al.

Neurology 2004;63;913-915

DOI 10.1212/01.WNL.0000137274.93125.46

This information is current as of September 13, 2004

\section{Updated Information \& \\ Services}

Supplementary Material

References

Citations

Subspecialty Collections

Permissions \& Licensing

Reprints including high resolution figures, can be found at:

http://www.neurology.org/content/63/5/913.full.html

Supplementary material can be found at:

http://www.neurology.org/content/supp1/2004/08/24/63.5.913.DC1

This article cites 10 articles, 3 of which you can access for free at: http://www.neurology.org/content/63/5/913.full.html\#\#ref-list-1

This article has been cited by 5 HighWire-hosted articles: http://www.neurology.org/content/63/5/913.full.html\#\#otherarticles

This article, along with others on similar topics, appears in the following collection(s):

Alzheimer's disease

http://www.neurology.org//cgi/collection/alzheimers_disease

PET

http://www.neurology.org//cgi/collection/pet

Information about reproducing this article in parts (figures,tables) or in its entirety can be found online at:

http://www.neurology.org/misc/about.xhtml\#permissions

Information about ordering reprints can be found online:

http://www.neurology.org/misc/addir.xhtml\#reprintsus

Neurology ${ }^{\circledR}$ is the official journal of the American Academy of Neurology. Published continuously since 1951, it is now a weekly with 48 issues per year. Copyright . All rights reserved. Print ISSN: 0028-3878. Online ISSN: 1526-632X.

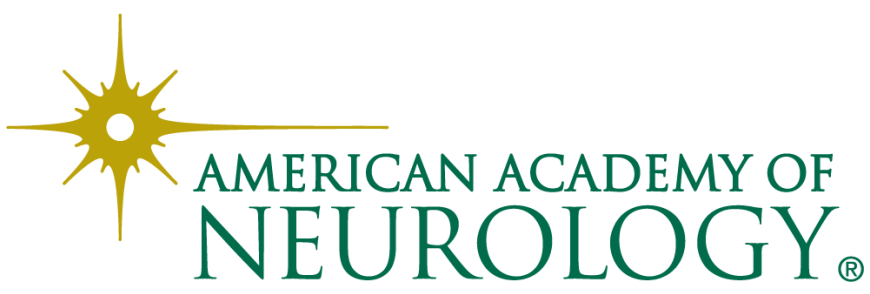

